Editorial

\title{
Coatings Best Paper Award 2015
}

\author{
Alessandro Lavacchi \\ Istituto di Chimica dei Composti OrganoMetallici (ICCOM-CNR), Via Madonna del Piano 10, \\ 50019 Sesto Fiorentino, Firenze, Italy; E-Mail: alessandro.lavacchi@iccom.cnr.it
}

Received: 17 June 2015/ Accepted: 18 June 2015 / Published: 19 June 2015

With the start of 2015, Coatings is instituting an annual award to recognize outstanding papers related to coatings and surface engineering that meet the aims, scope and high standards of this journal. We are pleased to announce the first "Coatings Best Paper Award" for 2015.

This year, the top papers were selected among all full research articles published in 2014 and 2013. Nominations were solicited from the Editorial Office of Coatings based on the citations and downloads.

The following three papers were awarded:

\section{Best Paper Award}

1st Prize

\section{Marcello Fidaleo, Nadia Bortone, Mark Schulte and Michael C. Flickinger}

Ink-jet Printing of Gluconobacter Oxydans: Micropatterned Coatings as High Surface-to-Volume Ratio Bio-Reactive Coatings

Coatings 2014, 4(1), 1-17; doi:10.3390/coatings4010001

Available online: http://www.mdpi.com/2079-6412/4/1/1

"The impact on society of the coatings under research in this article is very high."-Prof. Dr. Anibal Maury-Ramirez

"Very interesting paper describing a novel technology for microbial biosensors."-Prof. Dr. Maria Cristina Tanzi

\section{2nd Prize}

Andrea Milanti, Heli Koivuluoto, Petri Vuoristo, Giovanni Bolelli, Francesco Bozza and Luca Lusvarghi Microstructural Characteristics and Tribological Behavior of HVOF-Sprayed Novel Fe-Based Alloy Coatings Coatings 2014, 4(1), 98-120; doi:10.3390/coatings4010098

Available online: http://www.mdpi.com/2079-6412/4/1/98 
"The characterization work of the coatings done in this article is complete and very useful for other developments. "-Prof. Dr. Anibal Maury-Ramirez

"Comprehensive study with well-considered conclusions presented."-Dr. Gordon Armstrong "Clearly the best paper; very good mechanical results, nice characterization."-Prof. Dr. Giovanni Zangari

"Interesting paper with good results for specialized practical application."-Prof. Dr. Maria Cristina Tanzi

3rd Prize

Lamia Znaidi, Tahar Touam, Dominique Vrel, Nacer Souded, Sana Ben Yahia, Ovidiu Brinza, Alexis Fischer and Azzedine Boudrioua

AZO Thin Films by Sol-Gel Process for Integrated Optics

Coatings 2013, 3(3), 126-139; doi:10.3390/coatings3030126

Available online: http://www.mdpi.com/2079-6412/3/3/126

"Good paper with interesting results for optical waveguiding applications." -Prof. Dr. Maria Cristina Tanzi

These three outstanding papers are valuable contributions to Coatings and its engineering field. On behalf of the Prize Awarding Committee and the Editorial Board of Coatings, we would like to congratulate these three teams for their excellent work. In recognition of their accomplishment, the corresponding authors of these three best papers, Dr. Marcello Fidaleo, Dr. Andrea Milanti, and Dr. Lamia Znaidi will receive the privilege to publish an additional paper free of charge in open access format in Coatings after the usual peer-review procedure.

\section{Prize Awarding Committee}

Editor-in-Chief

Dr. Alessandro Lavacchi

Istituto di Chimica dei Composti OrganoMetallici (ICCOM-CNR), Via Madonna del Piano 10, 50019 Sesto Fiorentino, Firenze, Italy

E-Mail: lavacchi@mdpi.com

Founding Editor-in-Chief

Prof. Dr. Ugo Bardi

Dipartimento di Scienze della Terra, c/o Dipartimento di Chimica, Polo Scientifico di Sesto Fiorentino, Università di Firenze, Via Della Lastruccia 3, 50019 Sesto Fiorentino (Fi), Italy

E-Mail: ugo.bardi@unifi.it

\section{Editorial Board Member}

Dr. Gordon Armstrong

Irish Centre for Composites Research, Materials \& Surface Science Institute, University of Limerick Castletroy, Co. Limerick, Ireland

E-Mail: Gordon.Armstrong@ul.ie 
Editorial Board Member

Prof. Dr. Anibal Maury-Ramirez

Civil and Industrial Engineering Department, Engineering Faculty, Pontificia Universidad Javeriana Cali, Calle 18 \# 118-250, Cali, Colombia

E-Mail: anibal.maury@javerianacali.edu.co

Editorial Board Member

Prof. Dr. Maria Cristina Tanzi

Biomaterials laboratory, Department of Chemistry, Materials and Chemical Engineering 'G. Natta', Politecnico di Milano, Italy; INSTM Local Unit Politecnico di Milano, Milan, Italy

E-Mail: mariacristina.tanzi@polimi.it

\section{Editorial Board Member}

Prof. Dr. Giovanni Zangari

Department of Materials Science and Engineering, University of Virginia, 395 McCormick Rd, P.O. Box 400745, Charlottesvile, VA 22904-4745, USA

E-Mail: gz3e@virginia.edu

(C) 2015 by the author; licensee MDPI, Basel, Switzerland. This article is an open access article distributed under the terms and conditions of the Creative Commons Attribution license (http://creativecommons.org/licenses/by/4.0/). 